\title{
Vida cotidiana en las postrimerías de El Paso colonial
}

\author{
por \\ Víctor Orozco ${ }^{1}$ \\ Universidad Autónoma de Ciudad Juárez-México
}

\begin{abstract}
El propósito del artículo es ofrecer a los lectores un relato histórico de hechos, situaciones y procesos ocurridos en El Paso del Norte (Hoy Ciudad Juárez) durante ciertos momentos de la segunda mitad de la centuria XVIII y la primera de la XIX. El hilo conductor es la vida cotidiana de los pobladores, que comprende ámbitos privados y públicos. Se integran, de esta suerte, modos y costumbres, nombres, relaciones jurídicas y políticas, economía, religión, entre otras prácticas sociales. Los protagonistas son casi siempre hombres y mujeres anónimos o desconocidos para la historia. La idea central es que la narración ayude a mirar más de cerca la historia de esta ciudad, con la ayuda del microscopio, y a comprenderla desde esta perspectiva. He supuesto que estas narraciones servirán para alimentar el deseo o la inspiración de nuevas investigaciones, arribar a conclusiones útiles para los lectores o que su lectura proporcionará algún deleite por el conocimiento del pasado. El trabajo descansa en fuentes documentales primarias del Archivo Histórico Municipal de Juárez (AHMJ) básicamente ${ }^{2}$.

Palabras Clave: Paso del Norte; sociedad colonial; clases; indios; españoles; vida cotidiana.
\end{abstract}

${ }^{1}$ El autor es doctor por la Universidad Nacional Autónoma de México. Ha desempeñado su labor como profesor e investigador en varias universidades mexicanas. Ha publicado varios libros de historia de su país, entre ellos: El estado de Chihuahua en el parto de la Nación, México, Plaza y Valdez, 2007 (1. a reimpresión, 2010), ¿Hidalgo o Iturbide? Un viejo dilema y su significado en el nacionalismo mexicano, Doble Hélice Editores, México, 2005 y $R e-$ flexiones sobre la Historia Nacional, Universidad Autónoma de Ciudad Juárez, 2011. Pertenece al Sistema Nacional de Investigadores, nivel II.

2 Consulté este acervo documental en el original, mismo al que me refiero como AHMJ, Ciudad Juárez y en la copia en microfilm existente en las colecciones especiales de la Biblioteca Central de la Universidad Autónoma de Ciudad Juárez, que recientemente fue denominada Carlos Montemayor. En cada caso, cito la fuente precisa. 
Ubicados en los confines del mundo ibérico, los vecinos e indios del pueblo de El Paso del Norte - que también se llamaba Real Presidio del Passo del Río del Norte o Pueblo de Nuestra Señora de Guadalupe del Passo del Río del Norte, o Pueblo de Nuestra Señora de Guadalupe Real Presidio de Nuestra Señora del Pilar y Señor San José del Passo del Río del Norte, nombre este último que parece una letanía - sumaban hacia la sexta década del siglo XVIII 4.750 personas, contando a San Lorenzo el Real, San Antonio de Senecú, San Antonio de la Isleta, la Purísima Concepción del Socorro y la Hacienda de los Tiburcios, donde posteriormente se instaló el presidio de San Elizario ${ }^{3}$.

El Paso concentraba al $80 \%$ de los habitantes que, al igual que muchos otros poblados del imperio español, había tomado su nombre de un paso natural; en el caso, aquel por donde el río del Norte cruzaba la sierra. Todos pertenecían a la jurisdicción política y administrativa del Nuevo México, desde que Juan de Oñate había tomado posesión de estas tierras hacia 1598 en nombre del rey de España buscando al «Nuevo» México.

A diferencia de las grandes extensiones que caracterizaron a otras regiones del septentrión novohispano, en la de El Paso crecieron una gran cantidad de pequeñas y minúsculas propiedades, en virtud de que estaban dedicadas a la agricultura intensiva, principalmente de uvas y árboles frutales. Por ejemplo, hacia 1754, en el pueblo de Socorro se encontraban registrados 49 títulos de propiedad de tierras y solares con huertas; por las mismas fechas, otra relación de documentos guardados en el archivo del capitán y justicia mayor de El Paso contiene una gran cantidad de registros de propiedades o contratos y testamentos.

De hecho, El Paso y demás pueblos ribereños se componían de un largo corredor de huertos, más que de caseríos con una plaza y una iglesia centrales, distintivo urbanístico de los asentamientos hispanos; la misión de Guadalupe, que luego fue la iglesia parroquial, se ubicaba más bien en uno de los extremos. Esta división de la propiedad territorial constituye la primera explicación de la alta densidad poblacional alcanzada por los pueblos del río del Norte, si se le compara con la rala demografía de extensísimas porciones de Nuevo México y de Chihuahua, exceptuando desde luego a los asentamientos mineros. Hacia el norte, se caminaban unas ciento treinta leguas desde El Paso antes de llegar a Alburquerque, la primera población de relativa importancia.

\footnotetext{
3 Tamarón y Romeral, 1937.
} 
Rumbo al sur, sucedía lo mismo hasta la villa de San Felipe el Real de Chihuahua, situada a noventa leguas de distancia.

Tal despoblamiento, característico de los territorios norteños, fue una de las preocupaciones centrales de las autoridades coloniales. Primero, porque ello favorecía las incursiones indígenas, principalmente de apaches, que desde mediados del siglo XVIII fueron en incremento; y segundo, porque ya se advertía el expansionismo inglés, sobre todo después del triunfo británico sobre Francia en 1759. Así que los pueblos del río del Norte representaban un logro de gran relevancia en los esfuerzos para poblar el septentrión, aunque se veían casi siempre obstaculizados por el interés de los grandes propietarios, reacios a perder el dominio de sus grandes posesiones, como lo asentaba en sus informes el mariscal Nemesio Salcedo, comandante de las Provincias Internas de Occidente de 1802 a $1813^{4}$. Debe señalarse, por otra parte, que ya desde la época prehispánica la zona se distinguía por su concentración demográfica, debida con seguridad a la disponibilidad de agua y a la riqueza de la fauna.

El Paso era, en la segunda mitad del siglo XVIII, un asentamiento en el que convivían varios grupos étnicos que tenían, de acuerdo con el sistema del antiguo régimen, un estatuto diferente para cada uno de ellos. En primer lugar, estaban los españoles casados por lo general con alguna criolla. En segundo lugar, estaban los descendientes de estos matrimonios, quienes componían el grueso de los propietarios por la vía de la herencia. Seguían los mestizos, ocupados en labores de arriería y en todos los trabajos del campo, sobre todo, en el cultivo de árboles frutales y viñedos.

A todos estos grupos se les ubicaba bajo el rubro genérico de «españoles y gentes de otras clases» en las listas o padrones. Estos se instalaban en los pueblos como vecinos, lo que significaba que tenían varios derechos y obligaciones; entre los primeros, que podían comerciar con sus tierras y por tanto cambiar de domicilio; entre las segundas, que debían pagar impuestos, diezmos y primicias.

Por último, genéricamente se llamaba «indios» a un conglomerado de diversas matrices, que si nos guiamos por la manera como se dirigían a sus componentes el resto de los pobladores, importaba poco precisar. Había tiguas en Ysleta, apaches, piros y topiros en Socorro, y restos de los sumas en San Lorenzo, entre otros. A diferencia de los españoles, quienes nunca elegían a sus mandos, los indios nombraban cada año a sus propios gobernadorcillos, que fungían como autoridades intermedias y debían ser aceptados por el te-

\footnotetext{
4 Salcedo y Salcedo, 1990.
} 
niente de gobernador de El Paso. El estatuto de «indios» no les permitía convertirse en vecinos, pues no eran dueños individuales de las tierras, sino que estas les eran asignadas por la Corona. No podían vivir fuera de la comunidad y no pagaban impuestos personales; en cambio, debían entregar los tributos a los que se sujetaba en conjunto la comunidad y pagar, a veces entre rezongos, las sobrevivientes bulas de la santa cruzada cuya compra era hipotéticamente voluntaria.

Poco a poco se fue dando un proceso de conversión de los indios de misión a vecinos de los pueblos, aunque no sin resistencia de las autoridades. Por ejemplo, el 23 de septiembre de 1804, el gobernador de Nuevo México respondió negativamente a la solicitud de Juan Pedro Romero, indio de Senecú, quien pretendía mutar su condición por la de vecino argumentando que:

Habiendo notado la experiencia que los pueblos de El Paso disminuyen considerablemente, siendo uno de los motivos que los naturales pasan a la clase de vecinos para tener mayor libertad sin tener pertenencias fuera de una legua del pueblo. Que Juan Pedro Romero justifique tener fuera de la legua del pueblo de Senecú tierras suficientes para mantenerse él y su familia se le conceda la licencia que invoca y de no ser así permanezca en su misión donde goza de muchas prerrogativas y distinciones que no debe despreciar ni privar de ellas a los demás yndios con su mal ejemplo a pretexto de pagar diezmos y primicias de que SM los tiene exonerados $^{5}$.

Los indios eran llamados además «hijos» de los pueblos, para diferenciarlos de los «vecinos», que no necesariamente eran naturales del lugar. La condición y el nombre de «indio» permanecían como señales de referencia individual o colectiva. Por ejemplo, se hablaba de un predio que colindaba con «la antigua acequia de los indios», o bien se ordenaba comunicar las noticias y anunciar las subastas públicas al «indio Juan Nepomuceno», quien era el pregonero en 1783 .

Para los indios que no se habían sometido al dominio hispánico, ya fuera en sus propios pueblos o en los nuevos, se reservaba el término de «bárbaros». Cuando se les capturaba, era usual que se les enviase a los obrajes de la hacienda de Encinillas (en el camino a Chihuahua) reducidos a la categoría de esclavos o gañanes. Si eran niños, acababan asimilados como sirvientes, peones y aun soldados, llamándoseles «genízaros», significando con ello su procedencia incierta, producto quizá del cruce entre individuos de diversas na-

5 Oficio del Gobernador de Nuevo México, 23 de septiembre de 1804, AHMJ, Ciudad Juárez, caja 1804-1806 (en esta y en todas las citas textuales que siguen se respetó la ortografía original). 
ciones indígenas. Con el tiempo, los descendientes de estos últimos llegaron a formar el grueso de la población indígena en el Nuevo México.

En los inicios del siglo XIX, la mayoría de los pobladores en los pueblos era clasificada como españoles o de otras clases, comprendiendo en esta categoría a todos los que no eran indios, esto es, a los criollos y mestizos, estos últimos en franco ascenso como ocurría en toda la Nueva España. En el cuadro que sigue, originado en un informe misional, se muestra esta composición.

\begin{tabular}{|l|c|c|c|c|}
\hline \multicolumn{1}{|c|}{ Pueblo } & Ministros & Yndios & $\begin{array}{c}\text { Españoles y } \\
\text { gentes de otras } \\
\text { clases }\end{array}$ & Total de almas \\
\hline Passo & 2 & 221 & 3.749 & 3.970 \\
\hline Real & 1 & 30 & 275 & 305 \\
\hline Senecú & 1 & 318 & 185 & 503 \\
\hline Ysleta & 1 & 239 & 202 & 441 \\
\hline Socorro & 1 & 50 & 558 & 608 \\
\hline Total & & 858 & 4.969 & 5.827 \\
\hline
\end{tabular}

Fuente: Provincia de Nuevo México, Jurisdicción del Passo del Norte. Noticia de las misiones que ocupan los clérigos y religiosos de la provincia del Santo Evangelio en dicha jurisdicción. Sus progresos y demostración desde el año de mil setecientos noventa y tres hasta el de mil ochocientos dos. Número de ministros que las sirven. Sínodos que gozan y total de almas con distinción de clases y sexos (AHMJ, caja 1804).

En el informe se dice que los pocos sumas que quedaban en el real de San Lorenzo entendían su idioma, aunque hablaban mejor el castellano. Por su parte, los piros de Senecú y los tiguas de Ysleta hablaban tanto su idioma como el español. Aparte estaban los apaches, que aun cuando no se establecían en ningún pueblo de manera permanente, estaban siempre en contacto y muchos de ellos eran aliados de los novohispanos, a quienes servían con frecuencia como rastreadores o huelleros en las expediciones contra distintas partidas de los de su misma nación. Así que en la plaza de El Paso, a la hora de juntarse para comerciar, se hablaban varias lenguas a la vez.

Es probable que, durante cerca de ciento cincuenta años a partir de que se establecieron los primeros asentamientos de hispanos, no se conociera en El Paso a ningún otro europeo. Hay noticia de dos franceses llegados seguramente de la Luisiana que fueron conducidos a Chihuahua por orden de la comandancia general el 12 de septiembre de 1806, y también de un norteamericano que en 1808 se encontraba en el pueblo trabajando como canalero. 
¿Qué tanto vivían los habitantes de El Paso y demás pueblos? Una estadística de 1805 revela que apenas un 2,6\% de los hombres pasaban de los 60 años, mientras que un $9 \%$ de los varones y un $10,2 \%$ de las mujeres rebasaba los 45. Era una sociedad joven, si la midiéramos con los patrones actuales, pues el $20 \%$ de sus miembros tenía menos de 12 años. El principal enemigo de la salud eran las epidemias como la viruela y el sarampión. La primera, que causó estragos durante siglos, fue relativamente controlada a partir de 1805, cuando llegó a estas tierras la vacuna descubierta en 1798 por el inglés Edward Jenner.

\section{LOS INDIOS ENEMIGOS}

De entre los indios que habitaban la región de El Paso, los apaches nunca se pacificaron, a pesar de que convivieron largamente con los vecinos españoles. Varias parcialidades de ellos se asentaron en derredor de los presidios cuando el gobierno virreinal les ofreció raciones, pero una porción considerable permaneció fiel a sus ancestrales hábitos de nomadismo y pillaje. Tal actitud de seguro no es ajena al trato que los vecinos daban a los apaches sometidos y medio asimilados, quienes asumían la condición de esclavos o de sirvientes cuyo estado era muy cercano al de la esclavitud.

Hacia la década de 1770 aumentaron las hostilidades entre vecinos e indios de paz por una parte y las parcialidades apaches por la otra. En el informe que el coronel Hugo O'Connor rindió al gobierno virreinal en 1776, se explaya en la descripción de haciendas y rancherías que fueron objeto de los ataques apaches, quienes robaban la caballada y con frecuencia hacían cautivos a pastores o leñeros. Aplicando una rigurosa política consistente en golpear a los hostiles, entregar raciones a los que se sometiesen, proporcionar bebidas embriagantes a todos y fomentar las desavenencias entre tribus hostiles como lipanes y gileños, los españoles consiguieron paces parciales en los inicios de 1790. Buena parte de la Nueva Vizcaya gozó entonces de cierta tranquilidad.

En El Paso, por 1804 y en los siguientes años, aumentaron gradualmente los robos y ataques apaches. Trozos de vecinos e indios armados (como se les llamaba a estas partidas y cuyos integrantes más tarde serían conocidos como «campañadores») entraban y salían constantemente de los pueblos en persecución de los apaches, quienes una noche sí y otra también consumaban asaltos. Unos informes típicos por estos meses son los siguientes:

El día 4 del presente mes llegó a este pueblo el capitán Antonio Bargas con doscientos setenta hombres que componen el cordón de la provincia del Nuevo 
México y 31 hombres de tropa incluso un enfermo. El día seis salió para Chihuahua el expresado Dn Antonio Bargas con el cordón de NM. El día 26 pasó por este pueblo con una partida para campaña el capitán Dn José Manrique y se le reunieron 30 vecinos... El mismo día marcharon para la provincia del NM 13 vecinos de ella y dos de ésta. El día 28 salió el capitancillo Maya con 9 gandules y 3 mugeres a cazar con término de 15 dias hasta los serros del Ptrillo y llevan siete bestias, les permití licencia por orden del capitán José Manrique 6 .

La forma, tácticas y armamento que se utilizaban en el combate contra los apaches, no eran muy diferentes a las usadas por estos, salvo que los guerreros indios se parecían mucho a los fantasmas, pues difícilmente eran encontrados y aun vistos. Por lo demás, ambos contendientes peleaban o más frecuentemente se rastreaban en pequeños grupos, y a la hora de la lucha usaban armamento similar. Una estadística de 1804 registra el número de individuos entre los 16 y los 60 años en disponibilidad de tomar las armas en El Paso y las cuatro rancherías anexas, encontrándose que había 1.169 vecinos y 192 indios que disponían de 396 escopetas, 156 pistolas, 468 lanzas y 8.635 arcos y flechas ${ }^{7}$. La zozobra en que vivían los habitantes de la zona disminuyó notablemente, si no es que desapareció, a partir de 1810, cuando se pactó una de las paces de mayor duración con los apaches y que duraría hasta 1831 .

\section{Poblamiento y FUNDACIÓN DEl CARRIZAL}

A partir de la población existente en El Paso, se procuró fundar nuevos asentamientos. Así, en 1758 se dispuso el establecimiento de cincuenta familias en el paraje denominado el Carrizal, que antes había formado parte de la hacienda propiedad de Mateo de la Peña, vecino de El Paso, despoblada a la sazón por los ataques de apaches gileños. Se ordenó al capitán Manuel Antonio San Juan, capitán vitalicio y justicia mayor del presidio de El Paso del Río del Norte y su jurisdicción, para que reclutara en los pueblos y rancherías a los futuros pobladores. Diez días después de haber recibido el despacho comenzó su tarea y el 27 de febrero de 1758 se alistaron las primeras familias, que eran las de aquellos que carecían de tierra ${ }^{8}$. Más tarde se apuntaron 47

${ }^{6}$ Carpeta sin nombre, AHMJ, Ciudad Juárez, caja 1804.

7 Estado general que manifiestan los vecinos que hay en dicha jurisdiccion e yndios de los pueblos que pueden tomar las armas desde la edad de diez y seis a sesenta años con expresion de los caballos y armas. AHMJ, Ciudad Juárez, caja 1804.

8 Despacho mandado por el coronel Mateo Antonio de Mendoza, capitán general y gobernador del reyno de la Nueva Vizcaya, 27 de febrero de 1758, microfilm del AHMJ, Colecciones Especiales de la Biblioteca Central-Carlos Montemayor de la Universidad Autóno- 
familias: 27 de El Paso, 8 de Los Tiburcios, 1 de Socorro, 1 de Isleta, 5 de Senecú y 5 del real de San Lorenzo.

A cada una de las familias se les debían asignar parcelas suficientes para su sostenimiento, tomándolas de las superficies realengas, si las hubiere, y aun de las particulares, dejando para resolver después los conflictos que se suscitaren por las reclamaciones usuales de los hacendados, ya fueren los antiguos o los colindantes. También se les prohibió que enajenaran las parcelas durante los primeros diez años, para evitar la «perjudicialísima» (sic) apropiación de grandes extensiones por parte de un individuo, que no podía trabajar por sí solo.

Al Carrizal llegaron con el plano de su nuevo pueblo, compuesto de treinta cuadras de sesenta por sesenta varas cada una, con la plaza y la iglesia ubicadas justamente en el centro. Cada familia se aprontó con sus parcas provisiones e implementos que les fueron asignados: una cuera, una escopeta, lanza, espada, dos caballos, una libra de pólvora, una libra de balas, una pun-

ma de Ciudad Juárez, Ciudad Juárez, rollo 036, expediente con varios documentos relativos a la colonización-fundación del Carrizal. Es costumbre tener como fundadores de las poblaciones a clérigos, militares, ricos mineros o hacendados, sobre todo cuando la empresa tiene éxito. Se olvida casi siempre a los modestos labradores, que iban a los nuevos lugares junto con sus familias afrontando todas las inclemencias y peligros, sobre todo en tierras hostiles para ellos como lo eran estas del norte novohispano. Durante los siguientes cien años a su establecimiento, el Carrizal cumplió la función asignada de servir como antemural a las incursiones de los apaches, hasta que casi desapareció después de que el ferrocarril pasó por otro sitio cercano, donde se fundó villa Ahumada. Estos aferrados campesinos paseños y sus descendientes defendieron las tierras contra viento y marea, así que vale recordar y consignar sus nombres: Antonio Giner Provencio, casado con María Dolores Domínguez, con cinco hijos; Juan Luis Taphoya, casado con María Durán, con una hija; Domingo de Rivera, casado con Diega Trujillo, con cinco hijos; Miguel de Herrera, casado con Prudencia Madrid, con una hija; Ignacio Delphín, casado con Romelia García, con dos hijos; Sebastián Delphín, casado con María Sánchez, con dos hijos; Antonio Blas Trujillo, casado con Juana María Naranjo, con tres hijos; Thomás Romero, casado con María Josefa Joaquina, con un hijo; Vicente Rivera, casado con Antonia Capeti, con tres hijos; Nicolás Tolentino Fuentes Mendoza, casado con María Pasquala Lucero, con tres hijos; Pasqual Brito, casado con María Antonia; Miguel Antonio de Herrera, casado con Juana de la Peña, con tres hijos; Julián Rodríguez, casado con Juana Castellano; Jorge Valencia, casado con María de la Cruz; Ramón Palomino, con Antonia Lucero, su madre viuda y otro hermano; Gerónimo Antonio Barela, casado con Antonia Mathiana García; Marcial de Rivera, viudo, con tres hijos varones; Salvador Naranjo, casado con Victoria Durán, con dos hijas; Francisco Jaramillo, casado con Manuela Sánchez, con quatro [sic] hijos; Pedro Venegas, casado con Petronia Cisneros; Marcos Quinteros, soltero, mayor de veinticinco años; Bernardo Sandoval, casado con Antonia Lucero; Cristóbal de Abalos, casado con Isabel Téllez; Joseph María Abalos, casado con Eusebia López; Nicolás Alphonso, casado con Gerónima Naranjo, con dos hijos. 
ta de reja, un azadón, una coa, un hacha, una yunta de novillos y diez fanegas de maíz o de trigo.

Unos años después, el marqués de Rubí, que inspeccionaba todo el septentrión de la Nueva España por órdenes del virrey Croix, a su paso por el Carrizal asentó en su informe que estaba habitado por treinta familias pobres y «... mal habilitadas desde su formación» ${ }^{9}$. La fundación del Carrizal con pobladores originarios de El Paso y rancherías circunvecinas indica la importancia que tenían estos asentamientos y la relativamente alta densidad demográfica que habían alcanzado, como para derivar habitantes hacia nuevos puntos de colonización.

\section{PRODUCCIÓN Y COMERCIO}

Las feraces riberas del río del Norte, como se le llamaba comúnmente, habían adoptado perfectamente las plantas importadas por los europeos y eran pródigas en la producción de uvas, manzanas, duraznos y peras. El valor de la riqueza se medía sobre todo por la cantidad de cepas y de árboles frutales, tasándose también los álamos, abundantes en las vegas del río y altamente apreciados por su madera y por la sombra que brindaban. Por ejemplo, en el testamento otorgado el 7 de noviembre de 1754 por Juana de Herrera, esposa que fue de Francisco Tafoya, se dejan bienes por valor de 2.466 pesos y 4 reales, distribuidos de la siguiente manera: casa, 187 pesos 4 reales; ajuar, 214; tierras, 125; viña y árboles, 1.940 pesos; equivalentes a otras tantas plantas, valuadas a un peso por unidad ${ }^{10}$.

El poblado era asiento de fortunas que sumaban cantidades respetables, como la del comerciante Francisco Xavier Bernal, quien, al fallecer en 1763, dejó a sus herederos bienes por 7.350 pesos. Se entiende la magnitud de esta cantidad si consideramos el salario de sus trabajadores anotado más abajo. El inventario de mercancías comprendía telas, una variedad de joyas con fina pedrería, ropa, una miscelánea de artículos empleados en las tareas cotidianas del hogar o de la agricultura y el transporte, así como pipas, barriles, alambiques, cazos y todo lo necesario para poner a funcionar a una viña. En suma,

\footnotetext{
9 Velázquez, 1982: 41.

10 Testamento otorgado el 7 de noviembre de 1754 por Juana de Herrera, esposa que fue de Francisco Tafoya, microfilm del AHMJ, Colecciones Especiales de la Biblioteca Central-Carlos Montemayor de la Universidad Autónoma de Ciudad Juárez, Ciudad Juárez, rollo 028.
} 
se trataba de una tienda bien surtida, que no podrían imaginar quienes suponen que El Paso era una población aislada y miserable ${ }^{11}$.

Un testamento anterior, en el cual se revela también esta acumulación de riqueza generada en El Paso, es el de Phelipe Calderón y Bustamante, quien falleció en 1754. Este propietario, originario de las montañas del arzobispado de Burgos en los reynos de Castilla, heredó a su esposa y a una moza que había recogido, dos huertas con 3.500 matas de uva y una gran cantidad de bienes, sobre todo de barriles de aguardiente, así como créditos a su favor de varios deudores en Chihuahua, Cumpas, Janos y Oposura, entre otras poblaciones $^{12}$. El testamento más antiguo que se ha localizado es el de Antonio Valverde y Cossío, otorgado en $1728^{13}$. Era el ex gobernador del Nuevo México una de las personas más ricas de las provincias septentrionales de la Nueva España, y por los libros que se reseñan en el inventario de sus bienes, también amante de la ilustración, distintivo poco común en estos territorios.

Otro de los signos que muestran la vitalidad económica de la población se pone de manifiesto en la profusión de expedientes que contienen una variedad de procedimientos legales llevados por el capitán y justicia mayor. Además de los numerosos contratos que se celebraban, había prácticas económico-jurídicas propias de relaciones comerciales bastante sofisticadas, como la celebración de subastas públicas. En una de ellas, se sacaron a remate los bienes de un deudor en 1783, bajo los términos del siguiente pregón: «Quien quiere hacer postura a los vienes, muebles y raices que ha manifestado en este pueblo don Francisco Díaz Moradillos, con el fin de satisfacer a sus acreedores los cuales están abaluados en tres mil cuatrocientos ochenta y quatro pesos cinco y medio reales salvo error de pluma o suma, parezcan que se les admitirán las posturas, pujas o mejoras que hicieren...» ${ }^{14}$. Tal perorata fue cantada por el pregonero Juan Nepomuceno, «... indio ladino de la lengua castellana», por dos ocasiones en los lugares más concurridos.

Como es de suponerse, los habitantes de estas regiones norteñas eran consumados bebedores del aguardiente y del vino producidos en El Paso. El

11 Inventario y avalúo de los bienes de Francisco Xavier Bernal, microfilm del AHMJ, Colecciones Especiales de la Biblioteca Central-Carlos Montemayor de la Universidad Autónoma de Ciudad Juárez, Ciudad Juárez, rollo 026.

12 Testamento de Phelipe Calderón y Bustamante, 3 de julio de 1754, AHMJ, Ciudad Juárez, caja 1754.

13 Gudiño Quiroz, 1994.

14 Subasta ordenada por Eugenio Fernández, teniente de gobernador del pueblo del Passo, 2 de marzo de 1783, microfilm del AHMJ, Colecciones Especiales de la Biblioteca Central-Carlos Montemayor de la Universidad Autónoma de Ciudad Juárez, Ciudad Juárez, rollo 028 . 
procedimiento para elaborar el vino permaneció sin cambios por muchos años: se fabricaba un gran saco de cuero, que después de mojarse y ponerse a secar quedaba con la suficiente firmeza como para soportar sobre su boca una especie de parrilla también de cuero, con paredes de unas ocho pulgadas y pequeños agujeros en el fondo. El saco se colgaba de un armazón de vigas junto con la otra pieza, en la cual se colocaban las uvas, que un trabajador descalzo machacaba con fuertes pisadas hasta que escurría todo el zumo en el saco. Entonces se vertía el contenido en barriles en donde se dejaba fermentar por treinta días, al término de los cuales se pasaba a otros barriles durante dos meses, quedando listo el caldo para consumirse ${ }^{15}$.

El aguardiente requería un método más complicado, desde luego, porque provenía de la destilación de la uva. En este caso era indispensable poseer un alambique, artefacto de cobre bastante apreciado que los hispanos heredaron de los árabes. Una mula cargaba al menos dos barriles quintaleños de caldo, que a su vez contenían ciento veinte cuartillos cada uno con un valor de tres reales por unidad el aguardiente y poco más de real y medio el vino, de los cuales se iba surtiendo a cada poblado por donde pasaba la conducta, empezando por el de Janos, cuando el rumbo era hacia Sonora.

\section{DUEÑOS Y TRABAJADORES}

Los dueños de huertas y parcelas en las vegas del río empleaban a lo largo del año una tropa bastante nutrida de jornaleros, en tareas tales como los riegos, cultivos, pizcas y, al final, el procesamiento de manzanas, peras y sobre todo de las uvas. Las primeras eran deshidratadas y conservadas de esta manera por largos meses, lo que permitía su comercialización durante casi todo el año. Los viñedos constituían la fuente de ingresos más relevante, toda vez que eran la base de una industria con un alto valor agregado. En efecto, el aguardiente y el vino alcanzaban altos precios en todas las plazas de la Nueva Vizcaya, del Nuevo México y de Sonora, que conformaban un mercado cautivo para los productores y comerciantes de El Paso. Así se constata por los numerosos documentos que dan cuenta de las ventas que se concertaban en presidios, pueblos y en la villa de Chihuahua, de donde, a su vez, se trasladaban los barriles a otras regiones.

En derredor de las vinaterías giraban otras variadas actividades económicas, como la fabricación de barriles, tinas, pipas, cazos de cobre y aparejos de mulas. Desde luego, muchos artefactos y mercancías eran traídas del cen-

\footnotetext{
15 Timmons, 1990.
} 
tro del país y de ultramar, como los alambiques. También se requerían grandes cantidades de «jarciería», sombreros, canastos provistos por artesanos y obrajes del centro del país. Las telas de lana provenían del norte del Nuevo México (de donde llegaban por balsas durante las épocas en que el nivel de las aguas del río lo permitían) y del obraje de Encinillas.

En los viñedos y vinaterías trabajaban jornaleros de muy diversos orígenes: mestizos provenientes del centro del país, indígenas de las varias comunidades cercanas, españoles y criollos pobres o venidos a menos por la mala fortuna. El régimen prevaleciente entre dueños y trabajadores era el de la servidumbre, importada de los lares ibéricos, en donde había prevalecido por generaciones $\mathrm{y}$ al que por tanto estaban acostumbrados los propietarios. En tierras americanas, como ya se sabe, se combinó con otras relaciones sociales como las encomiendas durante el primer siglo de la conquista, sobre todo en las regiones mesoamericanas, o convivió con el esclavismo. Quizá el distintivo de mayor notoriedad que caracterizaba a este régimen señorial es que confería poderes extremos a los amos sobre los sirvientes; entre ellos, los de castigarlos y retenerlos hasta que acabaran de pagar sus deudas, originadas en el pago anticipado de raciones e indumentaria. Tales drogas (como también se les llamaba, quizá aludiendo a sus efectos malsanos) eran perpetuas con mucha frecuencia, por la desproporción entre su monto y el salario devengado por el deudor.

Sin embargo, la necesidad de fuerza de trabajo, sobre todo en ciertas épocas y fases del proceso de producción del vino, hacía que los dueños se disputaran a los trabajadores. En esos momentos, aumentaban los salarios y se aflojaban los lazos de sometimiento, sobre todo en casos de sirvientes con mayor experiencia o que tenían cierta capacidad para resistir y defenderse, regularmente españoles o criollos.

Aunque no eran muy comunes, también existían los esclavos. Por ejemplo, en el inventario de bienes mortuorios de Ana Valverde, llevado a cabo en 1762, se da cuenta de dos esclavos «sin escrituras» llamados Joseph y Thomasa, quienes fueron valuados en doscientos pesos, una cantidad bastante considerable. De la misma manera, en el inventario de bienes que pertenecieron al cura de la parroquia del pueblo de El Paso, José Ignacio Suárez, cuyo fallecimiento ocurrió en 1804, se registraron tres esclavos: Simón Bejereno, su madre y un hermano del primero. También Antonia Horcasitas, fallecida en 1805, era dueña de, al menos, un «esclavito» llamado Macedonio y de una esclava llamada María de la Luz.

A los indígenas se les reservaba un trato laboral en el cual se mezclaba una relación personal o individual con una comunitaria, a la manera de las 
cargas que soportaban los pueblos de indios, de las que eran responsables todos sus miembros, como sucedía con los tributos en especie o las compras de las bulas que se vendían en las cajas reales. En tales circunstancias, los dueños o amos constituían en garantes de las deudas de manera solidaria a familias o grupos de trabajadores y a la hora de las liquidaciones se compensaban créditos que tenían en contra de un sirviente con los que resultaban a favor de otro. Ello se advierte muy bien en los siguientes ejemplos, tomados de las cuentas que la sucesión de Mateo de la Peña, antiguo dueño de la hacienda del Carrizal, saldó con sus peones.

A fojas 79 del inventario del libro de peones consta debérsele a Antonio Durán 60 pesos 7 reales como parece a la foja 41 buelta del libro de caxa y debiendo Salvador Naranjo a fojas 74 del inventario y 55 buelta del libro 84 pesos 6 reales que los satisfizo trabajando en la huerta de dicho difunto Peña 2 meses y 12 días que a razón de 8 pesos al mes importan 20 pesos. 67 pesos 7 reales que satisfiso el citado Antonio Durán y este ha de volver a los vienes 3 pesos en cuya conformidad quedó el citado Durán pagado de lo que se le debía y Naranjo satisfizo al difunto lo que le quedó debiendo.

A fojas 76 buelta del inventario consta debérsele a Bartholomé Apache en la foja 62 buelta del libro de caxa 123 pesos y debiendo Andrés de la Cruz y sus hijos según fojas 74 buelta del inventario y 44 buelta del libro 167 pesos 5 reales estos se les abonaron con los 123 que se le debían a Bartholo y los 44 pesos restantes los debengaron después de la cuenta trabajando en la viña el dicho Andrés 2 meses y su hijo (ilegible) 2 meses y 12 dias y un mes 14 dias que trabajaron Joseph y Paulín con cuyo trabajo de todos quedaron pagados los vienes de lo que dicho Andrés y sus hijos le devían y Bartholo Apache satisfecho de lo que a el debían los vienes de Peña ${ }^{16}$.

Nota: Por «vienes» debe entenderse la «sucesión», como se le llamaría actualmente.

Se infiere que Durán y Naranjo, por una parte, y Bartholo Apache y Andrés Cruz, por la otra, estaban integrados en sendos grupos familiares o al menos vivían en comunidad, al igual que muchos otros sirvientes o peones de la lista a quienes se les hicieron compensaciones similares. Es interesante advertir cómo se articulaban todas las formas productivas y los diferentes

16 Cuentas que la sucesión de Mateo de la Peña, antiguo dueño de la hacienda de El Carrizal, saldó con sus peones, año de 1753, microfilm del AHMJ, Colecciones Especiales de la Biblioteca Central-Carlos Montemayor de la Universidad Autónoma de Ciudad Juárez, Ciudad Juárez, rollo 036. «Quentas que nosotros Zeledonio de Escorza y José Antonio de la Fuente como albaceas y tenedores de los vienes de Dn Mateo de la Peña formamos para que por ello venga en conocimiento de los peones pagados en todo y en parte a quienes dicho Peña quedó debiendo constantes en sus inventarios, como así mismo los que han satisfecho y pagado lo que quedaron debiendo a los vienes de dicho difunto y son los siguientes...». 
tipos de vínculos sociales, en una economía que exigía relativamente altas concentraciones de fuerza de trabajo sujetas a un sistema de salarios que son por definición pagos individualizados. Sin embargo, podemos imaginar que tanto a los propietarios hispanos como a los peones indígenas les era más fácil establecer una relación mediada por las comunidades o grupos, entre otras razones, por los problemas de comunicación existentes entre hablantes de lenguas distintas. Pero, también y sobre todo, se imponían estos tratos colectivos porque entre los peones indígenas prevalecía un espíritu comunitario radicalmente diferente al alma individualista de los europeos, de allí que pudiesen aceptar que su trabajo era al mismo tiempo trabajo de todos los de su clan o de su familia, si así podemos llamar a la congregación a la que pertenecían. Bastaba así al empleador entenderse con alguno de los indios que hablaban el castellano, para establecer la relación laboral con varios de la comunidad.

Una lista de los indios provenientes de Socorro y que trabajaron en las casas reales de El Paso, muestra en el mismo sentido cómo eran contratados en grupo por los gobernadores indígenas, quienes llevaban las cuentas y establecían la suma total de lo devengado por toda la cohorte ${ }^{17}$.

Considerando estas diferentes formas de propiedad y de relaciones productivas, la región de El Paso albergaba pues varios tipos de trabajadores y de fuentes de renta. El grueso de los vecinos vivía del trabajo familiar en sus propias parcelas; los propietarios de mayor acomodo empleaban trabajadores y percibían ganancias industriales y comerciales. El conglomerado de los indios de las misiones representaba una suerte de reserva laboral de la que se podía echar mano en cualquier momento, en la medida que se incrementasen las actividades económicas, o bien regresarla a sus aduares cuando aquellas se contraían. En un informe rendido por un visitador eclesiástico, se dice: «Los indios en estas misiones se mantienen de las siembras que cada uno hace

17 «Indios trabajadores de Socorro. Memoria y razón de los que trabajaron en las casas reales del pueblo del Passo del Río del Norte donde residía y vivía el difunto capitán San Juan y por orden de dicho Sr. venimos a trabajar los hijos de dicho pueblo los dias que se verán en esta memoria y son los siguientes...», 16 de marzo de 1765, microfilm del AHMJ, Colecciones Especiales de la Biblioteca Central-Carlos Montemayor de la Universidad Autónoma de Ciudad Juárez, Ciudad Juárez, rollo 030. Varios de los apellidos de los trabajadores provienen quizá de las lenguas indígenas, como el de Bartholo Achita o el de Luis Mendoza Tassique. Otros más, como el de Juan Pedro Parraleño, son quizá apodos convertidos en apellidos. En un lugar donde se producían melones en abundancia, varios se apellidaban Melón, como el mismo gobernador; y finalmente, también se hacía alusión en el apellido a la nación de donde se procedía, como en el caso de Domingo Apache. La mayoría había adoptado apellidos hispanos. 
en particular a cuyo fin tiene tierras señaladas por el gobierno y para adquirir el vestuario lo hacen así las indias como los indios trabajando a los vecinos a excepción de muchos que tienen sus viñas aunque cortas y algunos pocos de ganados mayor y menor con cuios esquilmos tienen lo necesario para su subsistencia» $^{18}$.

También se desplegaban otro tipo de relaciones laborales más cercanas a las del trabajo asalariado moderno. Entre la lista pagada por los albaceas de Mateo de la Peña, hubo al menos un caso diferente a los apuntados y es el de Gerardo Rueda, quien fue liquidado con 83 pesos; pero a su muerte, su viuda, Margarita Pedraza, entabló una demanda contra la sucesión de Peña, reclamándole una cantidad mayor, además de la propiedad de varios objetos, entre ellos, una escopeta, un arcabuz y un espadín que supuestamente el dueño le había vendido a su esposo ${ }^{19}$. Es presumible que Rueda fuera un empleado ubicado en un rango y en tareas distintas a los de los peones - quizá de vigilancia general, toda vez que Peña había sido dueño también de la hacienda del Carrizal, en donde se habían sufrido los primeros ataques de apaches gileños, como se ha dicho-, o es posible que fuera empleado como capataz. De cualquier manera, se repara en un vínculo laboral moderno típicamente salarial y por tanto personalísimo. Además, el caso despierta interés porque, en el juicio, la promovente emplea un copioso arsenal de recursos jurídicos, lo que indica un asesoramiento profesional bastante calificado, proporcionado por uno o varios jurisperitos radicados en El Paso, quienes dejaron huellas de su presencia en muchos otros expedientes judiciales.

Un sector de los trabajadores que estaba colocado en bastante mejor situación que los peones agrícolas era el de los arrieros, que se dividían en cargadores, sabaneros, aviadores y atajadores, ganando cada uno entre diez y doce pesos mensuales, mientras que los primeros percibían tres reales diarios, esto es, ocho pesos al mes. Se entiende la diferencia si se consideran los peligros que implicaban las largas jornadas y la exposición al peligro de ataques de los indios rebeldes. Además, poseían múltiples destrezas, pues eran lazadores, «huelleros», amansadores, cocineros, herreros, etcétera, conocimientos que evidentemente les daban una mayor calificación.

18 Provincia de Nuevo México, jurisdicción del Passo del Norte, Noticia de las misiones que ocupan los clérigos y religiosos de la provincia del Santo Evangelio en dicha jurisdicción. El Passo, 31 de diciembre de 1804, AHMJ, Ciudad Juárez, caja 1804.

19 Comparecencia de Margarita Pedraza, 1753, microfilm del AHMJ, Colecciones Especiales de la Biblioteca Central-Carlos Montemayor de la Universidad Autónoma de Ciudad Juárez, Ciudad Juárez, rollo 036. 
El trajín de las recuas compuestas por unos pocos animales o varias decenas no cesaba en todo el año, llevando los productos regionales a la villa de Chihuahua, por ejemplo, y luego de allí tomando flete para la ciudad de México, en donde se cargaban de nuevo para otra entrega en Guadalajara, en un recorrido que duraba largos meses, para regresar a El Paso con los cascos de los caldos y una gran variedad de mercaderías que se llevaban hasta las poblaciones del norte del Nuevo México. A la manera de los nombres que se pusieron después a los trenes que salían en fechas y horarios determinados, una de estas recuas era conocida como La Mexicana, porque cubría con regularidad la ruta de la capital del virreinato. Hacia la provincia de San Juan Bautista de Sonora, arrieros y mulas se desplazaban por la vía del puerto de Janos - que era también el único paso que permitía el tránsito de carretas a través de la Sierra Madre-, llegando con mucha frecuencia a las poblaciones de San Miguel de las Huertas y la Trinidad; hacia el este, por el Presidio de El Príncipe (Coyame), para llegar a Monclova e incluso hasta la Nueva Santander, de donde regresaban cargadas de piloncillo o plátanos secos. Con la villa de San Felipe el Real de Chihuahua se mantenía una intensa relación económica y burocrática, que se incrementó a partir de la ubicación allí de la sede de la Comandancia de las Provincias Internas de Occidente, cuando estas se fundaron en 1776. Entre los caminos más riesgosos destacaba el que se hacía hacia el interior del Nuevo México, al momento de separarse de la curva que hacía el río del Norte, para acortar el camino; desde ese punto se le conocía como la «Jornada del Muerto», nombre que duró casi todo el siglo XIX. A lo largo de este trayecto no se encontraba agua y la que se llevaba debía durar hasta el puesto de Socorro, ubicado unas cuarenta leguas más adelante, en pleno hábitat de indios hostiles.

Los arrieros, por todas estas razones y de muchas maneras, eran las estrellas del pueblo bajo: llegaban a conocer las enormes ciudades del centro, incluyendo la de México, podían hablar de parajes, personas y paisajes inimaginables para los peones acasillados, además de ser portadores de noticias, reales o inventadas. No abandonaban su condición de sirvientes, pero recibían su paga como individuos y estaban muchas veces en posición de negociar sus salarios.

\section{Prácticas JURÍDicas}

El uso de reglas jurídicas y la manera como estas se ponen en acto son elementos de una gran significación para entender el complejo de relaciones sociales y las mentalidades de cualquier sociedad. Los instrumentos jurídicos 
tienen la virtud de expresar indirectamente problemáticas sociales e individuales, así como de recoger informes sobre la vida económica, política, cultural o familiar, aunque sea de manera condensada. Es por ello que me ocupo ahora en analizar ciertas prácticas legales en El Paso, de las cuales ya se han dado más arriba algunas referencias.

Como se comprenderá, en una sociedad donde aún se encontraban fusionadas las instituciones civiles con las eclesiásticas, las fronteras que separaban las reglas propiamente religiosas de las civiles eran en extremo difusas o de plano inexistentes. Por definición, todos los habitantes profesaban la fe católica; los obispos eran simultáneamente funcionarios de la Corona — a la que debían su nombramiento- y de la Iglesia, e igual sucedía con los curas y tenientes de cura.

En razón de lo anterior, por ejemplo, las fórmulas solemnes empleadas en instrumentos públicos eran invocaciones religiosas sin las cuales aquellos carecían de validez. Uno de estos casos eran los testamentos, a cuyo otorgamiento eran, al parecer, muy afectos los vecinos de El Paso, pues hasta los que eran dueños de bienes bastante magros los otorgaban. Las palabras rituales y solemnes empleadas en los inicios de todas las disposiciones testamentarias eran las siguientes:

En el nombre de Dios Todopoderoso y de la Virgen María Santísima Nuestra Señora. Concebida en gracia desde el instante purísimo de su ser natural. Amén. Sepan cuantos la presente escritura de mi testamento vieren como yo... vecina(o) del pueblo de Nuestra Señora de Guadalupe del Passo del Río del Norte, estando enferma(o) en cama de la enfermedad que Dios ha sido servido darme y hallándome en entero juicio, memoria y entendimiento natural temiéndome de la muerte por ser cosa cierta y tan debida a toda creatura y deseando estar prevenida (o) y dispuestas las cosas de mi obligación para el descargo de mi conciencia y bien de mi alma:... ordeno este mi testamento en la manera y forma siguiente...20

El origen de estos protocolos que se reproducen en una gran cantidad de documentos de la época se pierde en el medioevo, pero fueron enfatizados durante la contrarreforma que en España y sus dominios tuvo una importancia decisiva para reforzar la autoridad del Estado y de la Iglesia. Quedaron al final como fórmulas congeladas en el tiempo, al igual que infinidad de usos lingüísticos.

El encargado de administrar justicia era el capitán general y justicia mayor, quien custodiaba y llevaba los archivos públicos en los que se conservaban títulos, contratos, mandatos, testamentos, procesos penales, etcétera. Los procedi-

20 Comunicación enviada al cura párroco por el teniente de caballería y de gobernador del pueblo del Paso, autoridad competente para seguir el proceso, AHMJ, Ciudad Juárez, caja 1804 . 
mientos judiciales, cuya matriz venía del derecho romano, eran sustancialmente iguales a los de ahora. Para el desahogo de la prueba testimonial, por ejemplo, se presentaba previamente un pliego de preguntas a los testigos, y en sus respuestas estos debían dar la razón de su dicho. En estos documentos judiciales se advierte — por cierto - el tránsito que se experimentó en México, del antiguo «vos» por el «usted», pues al dirigirse a la autoridad se empleaba la abreviatura VM o VMD por «vuestra merced», que derivó en «vuesused» y en «usted».

Si bien no eran muy frecuentes los delitos graves, de tiempo en tiempo se cometían homicidios, sobre todo a resultas de riñas. Uno de los procesos penales que llama la atención es el incoado en contra de María Josefa Yrollaga y de su presunto amante Martín Padilla, acusados de haber dado muerte al marido de la primera el 1 de julio de 1802. La inculpada se fugó de la cárcel cinco años después y se refugió en la iglesia parroquial, acudiendo a un antiquísimo medio de amparo todavía vigente en la época, como lo muestran los siguientes documentos.

El teniente de caballería y de gobernador del pueblo de El Paso, autoridad competente para seguir el proceso, envió al cura párroco la siguiente comunicación:

A VM de parte de SM (QDG) exhorto y requiero y de la mia ruego y suplico que luego que le sea presentada esta carta exhortatoria a la que declaro en nombre del Rey Nuestro Señor por caución juratoria mande se entregue dha refugiada a la justicia para que esta pueda en cumplimiento de su oficio practicar las diligencias prevenidas por derecho pues yo como ministro del Rey Nuestro Señor prometo en su real nombre que a la expresada Maria Josefa Yrollaga se le guardarán los fueros de inmunidad que le correspondan, que en hacerlo así cumplirá con las obligaciones de su empleo y a el tanto me ofrezco siempre que las de vM me sean presentadas en este juzgado de mi cargo en donde se fecha a los veintisiete días del mes de febrero de mil ochocientos siete.... ${ }^{21}$

Después de más de dos años de permanecer asilada en el templo, las autoridades eclesiásticas resolvieron que era improcedente el asilo y la entregaron a la justicia civil, según se lee a continuación:

Con vista a lo dictaminado por el promotor fiscal de la curia en decreto de 11 de agosto pasado, declara el Sr. procurador y Vi... general de este obispado, en conformidad de dicho dictamen que Maria Josefa Ydollaga presa en la real cárcel y refugiada en esta santa iglesia no goza de la inmunidad..., por ser su delito de los exceptuados en ella, en cuia virtud debuelbo a vм la caución juratoria que para extraerla de esta santa iglesia y seguridad de este juzgado me otorgó con fecha 27 de febrero de 1807 sirviéndose se acusarme el correspondiente recibo.

21 Idem. 
Dios Guarde a vm muchos años, Paso del Río del Norte septiembre 27 de $1809^{22}$.

La tardanza en la administración de la justicia continuó por varios años y todavía en 1812 seguía el proceso sin que hubiera recaído una sentencia. En ese año, el defensor lego de María Josefa alegaba que su defendida había pasado ya diez años y tres meses en la cárcel, y que cuando se cometió el delito apenas tenía 16 años de edad, por todo lo cual imploraba clemencia. Con razones parecidas se pronunció el defensor de Padilla. No encontré las constancias para saber cómo terminó este caso de «maricidio», según lo llamaron las autoridades judiciales. Su relevancia estriba en que hace patentes todos los mecanismos de administración de la justicia colonial, que en el caso se retardó especialmente porque a partir de 1810 se alteraron las comunicaciones, según lo informan las autoridades, lo que impidió el traslado del voluminoso expediente a las instancias superiores por temor a que se extraviara.

Por diferentes razones, tiene también interés el caso relacionado con el presunto robo que sufrieron los bienes pertenecientes a la sucesión del sacerdote José Ignacio Suárez, cuyo deceso he mencionado más arriba. Al parecer, apenas fallecido el clérigo, se sustrajeron de su casa utensilios de plata, un par de hebillas de oro para zapatos y otros enseres. Por otra parte, el autor de la sucesión no dejó testamento escrito, pero presuntamente dijo a su confesor, otro clérigo de Senecú, la forma en que se distribuirían sus bienes; entre ellos, una casa en Nazas, otra casa y un rancho en la villa de Chihuahua, y dispuso dar libertad a sus tres esclavos. Se planteaban dos problemas: uno, el de atribuir o no validez al dicho del confesor; y dos, si creer o no a los que decían que existieron los bienes.

Después de un año de exámenes y pesquisas, sometido el asunto al dictamen del licenciado Ignacio Minjárez, en la ciudad de Durango, este opinó valiéndose de una copiosa argumentación jurídica, apoyada en clásicos juristas romanos y en el derecho canónico, que debían tenerse por válidas las disposiciones testamentarias referentes a las casas donadas a una cofradía y a la libertad de los esclavos. También dictaminó que era cierta la sustracción de los valores apoyándose en: «... la declaración de Simón el esclavo, pues aunque sea de esta condición miserable su testimonio, en el caso es fidedigno y mayor de toda excepción», así como en «... varias deposiciones de testigos fidedignos para el caso presente, pues aunque casi todos sean mugeres declaran en negocio en que solo ellas pueden tener noticia... $\rangle^{23}$.

22 Idem.

23 Dictamen del licenciado Ignacio Minjárez, en la ciudad de Durango, 1804, AHMJ, Ciudad Juárez, caja 1804. 
Por tanto, el confesor, junto con varias mujeres acusadas, debía rendir de nuevo declaración sobre los bienes muebles, y una vez que estos aparecieran, debían ser adjudicados a los herederos ab intestato del cura, para lo cual había que girar exhorto a su lugar de origen en España y una vez que se comprobara la ausencia de parientes, se entregarían a la cámara real.

\section{HeRramientas y obJETOS DE USO PERSONAL}

Como puede suponerse por los oficios practicados en la región, las herramientas más comunes eran las usadas en la agricultura, la ganadería y en actividades relacionadas con ellas. Monturas, tenazas, martillos y clavos para herrar, tijeras para trasquilar, cuchillos capadores, fierros de herrar, palas, azadones, «coas» y rejas de arado, siempre figuraban en los inventarios, al igual que los antiguos artefactos para la carpintería como hachas, azuelas, martillos, sierras «troceras» y maneras, serruchos, formones, escoplos, barrenas y cinceles. También instrumentos para pesar y medir (como las romanas), tijeras y agujas de $\operatorname{arria}^{24}$, agujas comunes, tinteros y plumas. Asimismo, cazos, pipas, pipotes, alambiques y barriles (que era costumbre alquilar).

Las casas de los pobres tenían apenas lo indispensable para comer y dormir. La indumentaria de sus habitantes se reducía a calzones (pantalones) - frecuentemente de gamuza-, largas faldas las mujeres y camisas, huaraches o sandalias.

Los ricos, en cambio, eran poseedores de sofisticados utensilios como vajilla de plata, «tojabas» o «tojabillas» (especie de cubrecamas o de almohadas) con bordes de oro y plata, mantones de Manila, casacas, varios pares de zapatos, capas de Ruan y joyas diversas. Doña Ana Valverde, por ejemplo, cuando murió en 1762 tenía entre sus bienes de uso personal, aunque ya envejecidos:

Cuatro caxas de Mechoacán con cantoneras y chapas maltratadas.

1 tobajilla de thela negra con punta de plata de poco mas de dos dedos de ancho en 8 pesos.

Una dcha de thela salomónica maltratada con fleco de plata en 7 pesos.

Una dcha maltratada con fleco de oro y flores de plata en 3 pesos.

1 saya de melendere con flores... con su punta de plata... en 12 pesos.

${ }^{24}$ El término «de arria» probablemente venga de la palabra «arria», que significa recua, quizá por ser los arrieros quienes usaban estas grandes y toscas agujas para coser sacos y costales. 
1 dicha de capichola negra con listones...

1 dicha con su cotilla de terciopelo negro punta de plata bieja.

1 paño bordado algo maltratado en 4 pesos.

1 par de pulseras de perlas finas poco mas de Aljofar con 38 yilitos... 35 pesos.

1 par de dichas de Aljofarito con 38 ylos, sin chapetas son 19 pesos.

1 joya de pecho de oro guarnecida de esmeraldas mui empañadas y punta chica de diamante en 80 pesos.

1 salviyita sincelada con su jarro de plata... ${ }^{25}$.

También el sacerdote Juan Ignacio Suárez, ya mencionado, usaba en sus zapatos hebillas de oro y comía en vajilla de plata.

Cuando viajaban, los más pudientes llevaban pequeños cofres que guardaban artículos para el aseo y la buena apariencia, así como también aquellos indispensables para hacer frente a los percances del camino. Por ejemplo, en 1762 se perdió en un viaje a los presidios de Sonora el comerciante en vinos Antonio Dageló, a quien nunca se le volvió a ver ni vivo ni muerto, a pesar de que las pesquisas duraron meses y contaron con la pericia de indios exploradores y los puntuales informes de los arrieros que le acompañaban. Además de los barriles de vino y aguardiente, armas y aparejos, entre sus pertenencias tenía una cajita de viaje con cerradura y varios adminículos como navajas de rasurar, espejo, peynes, etc. ${ }^{26}$.

El extendido uso de todos estos utensilios personales muestra una población con importantes segmentos que podían gozar de excedentes económicos, gracias a un tipo de relaciones económicas cuyo soporte era la posesión de lotes ribereños altamente productivos. Sus jornaleros, a su vez, podían vestirse con harapos cotidianamente por lo caro de las prendas, pero estaban en condiciones de embriagarse sin muchas dificultades.

\section{TIEMPOS Y NOTICIAS}

El 3 de enero de 1761, don Manuel Antonio San Juan, personaje ya mencionado, mandó ejecutar la orden que se le enviaba de Santa Fe de Nuevo México, para pregonar «... a son de caja destemplada y por otros instrumentos fúnebres» la muerte de Fernando VI, Rey de las Españas, ocurrida el 24 de agosto de 1759. Salvo los muy pobres, a quienes se les eximió de la obliga-

25 Bienes de uso personal de Doña Ana Valverde, 1762, microfilm del AHMJ, Colecciones Especiales de la Biblioteca Central-Carlos Montemayor de la Universidad Autónoma de Ciudad Juárez, Ciudad Juárez, rollo 026.

26 Idem. 
ción, todos los demás que fueren cabezas de familia debieron vestirse de luto riguroso en cuanto se enteraran de lo avisado por los pregones que comunicaban el infausto acontecimiento, por otra parte también halagüeño, puesto que al tiempo se hacía saber que la corona de los «dominios de España y de las Indias» había recaído en Carlos III, hijo del fallecido y por ello miembro de la casa de Borbón ${ }^{27}$.

Se había tardado casi año y medio en recibirse el comunicado oficial del fallecimiento de su monarca y el encumbramiento de su sucesor. No se crea, sin embargo, que tanto demoraban usualmente las noticias venidas de la madre patria y menos las provenientes del centro del virreinato. En el caso comentado, el virrey Francisco Cajigal de la Vega había emitido el decreto para celebrar las exequias apenas en junio de 1760 y el correo proveniente de la ciudad de México atravesó el vecindario al menos dos meses antes para llegar hasta Santa Fe, la capital de Nuevo México. Allí, la autoridad superior tardó otro poco en tomar las providencias de rigor, para ordenar el regreso del decreto virreinal por el mismo camino que había llegado, remontando al menos ciento cincuenta leguas, que dobladas hacían más de la mitad de las quinientas que distaban entre sí la sede del virreinato y el poblado de El Paso.

Desde Durango, donde radicaba la silla episcopal y a donde se mandaban en consulta asuntos litigiosos por residir allí competentes abogados, los correos tardaban tres semanas. En cambio, un comunicado redactado en San Felipe el Real de Chihuahua, distante noventa leguas, tardaba una semana en llegar a las autoridades de El Paso, quienes lo copiaban y estaban comunicándolo a los vecinos apenas al día siguiente, haciéndose lo mismo dos días después en el real de San Lorenzo (donde se había colocado la milagrosa imagen traída por los huidos de la rebelión indígena de 1680, río arriba del Nuevo México). Unas seis décadas más tarde, en 1823, los ayuntamientos constitucionales de El Paso, Socorro y Senecú considerarían que tenía poco sentido recibir los comunicados de retorno, argumento que sirvió, entre otros, para sustentar su determinación de separarse del Nuevo México y unirse a la provincia de Chihuahua, que se estaba formando.

27 Comunicado de Antonio Marín del Valle a Manuel Antonio San Juan, enero 3 de 1761, microfilm del AHMJ, Colecciones Especiales de la Biblioteca Central-Carlos Montemayor de la Universidad Autónoma de Ciudad Juárez, Ciudad Juárez, rollo 026. 


\section{ENSEÑANZA DE LAS PRIMERAS LETRAS}

No obstante su lejanía de los grandes centros urbanos, en los pueblos del río del Norte se realizaban importantes esfuerzos para enseñar a leer y a escribir, así como los elementos de la aritmética, a un buen número de infantes. En 1806 había 558 niños en las escuelas de los pueblos del río del Norte, repartidos en cinco categorías o rangos, empezando por los más avanzados, que leían y escribían en carta, los que sabían leer en libro, en catones ${ }^{28}$, en cartilla y los que estaban aprendiendo a rezar. En El Paso había 424 niños distribuidos en cada uno de los siete partidos con sus profesores, de la siguiente manera: Partido de las Playas, José María García; Chamizal, Cristóbal Sáenz; del Centro, Antonio Serna; Barrial, Lorenzo Fuentes; Las Calaveras, Santos Rodríguez; Los Álamos, Benito del Villar; Álamo Gacho, Manuel García. En el real de San Lorenzo enseñaba Manuel Alvarado a 26 niños; en Senecú, José Mariano Peña, quien tenía treinta alumnos; en Ysleta, Pablo [ilegible] con 32; y finalmente en Socorro, el profesor era José Antonio Rubio y a sus lecciones iban 46 niños. En la estadística e informe, se indica que no se acompañaban todas las planas escritas por los alumnos, porque algunos no tenían papel y usaban pergamino. También se decía que varios niños no terminaban por ser pobres sus padres y necesitarlos para trabajar. Los puntillosos maestros presentaban además una lista con los nombres de los alumnos más aventajados, que dominaban ya la lectura, la escritura y las operaciones aritméticas ${ }^{29}$.

\section{INFERENCIAS Y CONCLUSIONES}

Por diversas experiencias investigativas conozco la riqueza del material histórico localizable en los archivos municipales. En su variada gama de escritos, es posible penetrar en la vida de las pequeñas colectividades y descifrar algunos de los códigos que marcan su existencia. Por lo que hace a los pueblos instalados a la vera del río Grande del Norte o río Bravo, el conjunto de estampas de su cotidianeidad aquí expuestas me permitió - y espero que a los lectores también- conocer cómo transcurrían los días en unas comunidades

28 Se llamaba «catones» a ciertas lecturas sencillas de vidas de santos o similares, con los que los niños se entrenaban en todas las posesiones hispánicas.

29 Provincia de Nuevo México, jurisdicción de El Passo, año de 1806, Estado general que manifiesta el numero de niños que existen en las escuelas asi en este pueblo como en los demás pueblos de su jurisdicción, AHMJ, Ciudad Juárez, caja 1804. 
ubicadas en la periferia del gigantesco imperio español en las vísperas de su disolución. Me sorprendió la vitalidad de su actividad, desarrollada en el seno de un tejido social en el que cohabitaban productores de vino en la antesala del capitalismo, comunidades indígenas tradicionales, idiomas vernáculos con el dominante traído por los europeos, conflictos pasionales, guerras entre los apaches indomables y los vecinos e indígenas aposentados, intensas prácticas jurídicas y, contra lo que pudiera pensarse, la operación de rudimentarias pero eficaces escuelas de primeras letras. Todo esto fue Paso del Norte, el remoto antecedente de la moderna y agobiada Ciudad Juárez, que, al final, puede comprenderse yendo, como siempre, a los orígenes, según esta idea tan cara a Marc Bloch y que también he asumido como brújula en mis indagaciones históricas.

\section{BIBLIOGRAFÍA}

Escobar, José U., Siete viajeros y unas apostillas, de Passo del Norte, introducción y notas por Darío Óscar Sánchez Reyes, México, Gobierno Municipal y Meridiano 107 Editores, 1997.

González de la Vara, Martín, Breve historia de Ciudad Juárez y su región, México, El Colegio de la Frontera Norte/UACJ, 2002.

Gudiño Quiroz, Rebeca A., Don Antonio Valverde y Cossío, gobernador de Nuevo México: una aproximación a su vida pública y privada, Ciudad Juárez, Chihuahua, UER-UACJ, Serie Cuadernos de Trabajo, 24, 1994.

Salcedo y Salcedo, Nemesio, Instrucción Reservada de Don Nemesio Salcedo y Salcedo, Comandante General de Provincias Internas a su Sucesor, introducción y notas por Isidro Vizcaya Canales, Chihuahua, Centro de Información del Estado de Chihuahua, 1990.

Tamarón y Romeral, Pedro, Demostración del vastísimo obispado de la Nueva Vizcaya 1765. Durango, Sinaloa, Sonora, Arizona, Nuevo México, Chihuahua, y porciones de Texas, Coahuila y Zacatecas (introducción bibliográfica y acotaciones de Vito Alessio Robles), México, Antigua Librería Robredo de José Porrúa e Hijos, 1937.

Timmons, W. H., A Borderlands History, El Paso, Texas, The University of Texas at El Paso, 1990.

Velázquez, María del Carmen (comp.), La frontera norte y la experiencia colonial, México, Secretaría de Relaciones Exteriores, 1982. 


\section{Archivos CONSULTADOS}

Archivo Histórico Municipal de Juárez (AHMJ).

Archivo Histórico Municipal de Chihuahua (AHMCH).

Fecha de recepción: 11 de marzo de 2011

Fecha de aceptación: 7 de junio de 2011

\section{Daily life in the aftermath of colonial El Paso}

The purpose of the paper is to offer readers a historical account of events, situations and processes that occurred in El Paso del Norte (now Ciudad Juárez) during particular times in the second half of the Eighteenth Century and the first half of the Nineteenth. The common thread between all of them is the daily life of residents, both inthe private and public spheres, which integrated manners and customs, names, legal and political relations, economy, religion, among other social practices.The main characters are almost always anonymous; men and women unknown to history. The central idea is that the narrative helps to put the history of this city under a microscope and by looking more closely we can understand it from this perspective. I have assumed that these stories will serve to fuel the desire or inspiration for new research, to arrive at conclusions which are useful to readers or provide some pleasure by reading for knowledge of the past. The work is based on primary documentary sources in the Juarez Municipal Archives (AHMJ).

Key words: Paso del Norte, colonial society, class, natives, Spaniards, daily life. 